\title{
Theory-Practice Gap: Challenges Experienced by Nursing Students at the Satellite Campus of a Higher Education Institution in Namibia
}

\author{
Saara Kerthu Hatupopi ${ }^{1} \&$ Vistolina Nuuyoma ${ }^{2}$ \\ ${ }^{1}$ Lecturer, School of Nursing, University of Namibia, Namibia \\ ${ }^{2}$ Senior Lecturer, School of Nursing, University of Namibia, Namibia \\ Correspondence: Vistolina Nuuyoma, Senior Lecturer School of Nursing, University of Namibia, Namibia. E-mail: \\ vistolina.nuuyoma@gmail.com; ORCiD (Vistolina Nuuyoma iD): https://orcid.org/0000-0002-5744-1355
}

Received: July 11, 2019

Accepted: July 31, 2019

Online Published: August 2, 2019

doi:10.5430/ijhe.v8n5p21

URL: https://doi.org/10.5430/ijhe.v8n5p21

\begin{abstract}
Theory practice gap is the discrepancies found between what students learn in the formal classroom setting and what they experience in the clinical settings. Observations reveal that nursing as practised is task-centred and students rarely get involved in anything approaching the total care of individual patients, thus leading to theory-practice gap. This study explored and described the challenges faced by Bachelor of Nursing (clinical) honours students when integrating theory into practice in the clinical settings.

The study, which was granted ethical clearances from two institutions, drew on an exploratory phenomenology methodology to gather data from ten nursing students registered at a satellite campus. The participants were purposively selected with data collected via focus group interviews. Thereafter, data were transcribed verbatim and analysed using content analysis. The study data collection and analysis adhered to ethical principles and quality measures in order to ensure credibility, transferability, dependability and confirmability. Nursing students experience challenges in integrating theory and practice. These challenges are grouped into four themes; theory verses practice, limited resources in clinical settings, discriminatory attitudes and communication barriers. Nursing students appreciated accompaniment and supervision by nurse educators. However, the accompaniment's impact on learning may be undermined through the students' limited exposure to clinical cases. Therefore, long-term strategies are recommended for effective integration of theory with practice.
\end{abstract}

Keywords: theory- practise gap, integration, nursing students, clinical learning environment, clinical settings, higher education

\section{Introduction}

Nursing education consists of two components and these are the theoretical aspect and clinical learning. Theoretical aspects, on the one hand, cater for the knowledge and insight that is rendered in the classroom. These aspects provide a platform for nursing students to understand nursing history, professionalism, the human body, diseases, and nursing procedures. Clinical learning, on the other hand, aims to improve the clinical skills and attributes of nursing. A clinical learning environment offers nursing students the opportunity to apply theory into practice (Saifan, Safieh, Milbes \& Shibly, 2015). There is, within the components of nursing education, still a challenge of a theory practice gap in nursing education (Maginnis \& Craxon, 2010; Davhana- Maselesele et al., 2001). Corlett et al. (2003) described a theory practice gap as the discrepancies found between what students learn in the formal classroom setting and what they experience in the clinical settings as detailed experiential learning. Observations reveal that nursing as practised is task-centred and students rarely gate involved in anything approaching the total care of individual patients (Manning \& Craxon, 2012), thus leading to theory-practice gap.

Students in clinical environments have to confirm to the way patients are nursed, which is task and procedure orientated (Chan, 2013). Chan (2013) further indicates that such students will experience vulnerability and a sense of isolation which will leave them marginalised and unable to bridge the gap between theory and practice. Another study conducted by Froelicher, (2012) in Jordan reports on the existence of contradictions between what was taught in class and simulation laboratory and what was practiced in clinical settings. The study notes that the contradictions resulted in the nursing students becoming confused, stressed and anxious, which may indicate that students are not adequately trained in preparation of the work that they will do after qualifying as professional nurses. Many factors account for 
the difficulties in controlling the clinical setting. These factors include attitudes of health care providers, lack of work ethics, the unit environment, the condition of equipment, and the conduct of patients and their family members. Ironically, such factors cannot be controlled by clinical instructors (Tiwaken, Curanto, Jose \& Davids, 2015). In addition, the clinical setting is very different from the classroom and can shock students in a major way that they end up struggling when it comes to the application of theoretical aspects into practice. Therefore, Clinical teaching and coaching is highly recommended.

A study carried out by Cassimjee and Bhengu, (2006) reveals that student's kwaZulu Natal South Africa were receiving insufficient clinical teaching and accompaniment. Waterston et al., (2006) found that students in the Gauteng Province of South Africa lack mentorship and role modelling. Finally, Dhavana-Maselesele (2001) noted that students in Free State presented high levels of stress due to limited teaching, registered nurses who rejected their teaching role in the wards, and the uncaring behaviour from the management in the clinical setting. All these factors may lead to theory-practice gap.

The clinical setting is always going through continuous changes, which always leave the setting complex (Nabolsi, et al., 2012). It can be argued that theoretical teaching alone cannot assist students on how to deal with such changes and challenges, yet if the students are without theoretical insight they will never be able to reflect on the rationale of practice, thus underscoring that the two cannot be isolated (Smith, Lawrence \& Todd, 2007). A study done by Moet et al., (2004) indicates that the clinical environment can influence the theory practice gap in students. The study noted the existence of a shortage of staff, limited equipment, high bed occupancy, financial constraints, and limited structure and organisation in a clinical placement. The observed factors can indeed lead to depression among staff and result further in the experienced staff having limited time and energy to see to the needs of the students. This then leads to the students' isolation, frustration, and inability to integrate theory into practice and this ultimately results in more attrition from the program (Mabuda et al., 2008).

Therefore, clinical settings should have clinical support structures where students can access mentorship and support. The students must also have clinical facilitators and work under the supervision of senior clinical staff. Such support basis will act as gates keepers in ensuring that students are able to function competently in the wards and integrate theory into practice sufficiently (Landers, 2011). Rhikhotso, Williams and De Wet (2014) recommend that maximum time should be spent with the student in the form of accompaniment in order to re-enforce theory integration in the clinical placements. This accompaniment will, as noted by Siganga and Jeggels (2014), prepare nursing students for all sorts of challenges that they may experience as professionals.

Members of the nursing profession generally face challenges when it comes to collaborating textbook description of clinical situations with the reality of practice (Smith et al., 2011). As lecturers and clinical facilitators, the researchers observed the theory-practice gap while conducting formative and summative evaluations of the nursing students. The observation was that students do not engage pro-actively during clinical teaching and learning. They are also unable to see the link between what is taught in the classroom to what they experience in the clinical learning environment. This challenge influences their clinical reasoning and performance in clinical practice. To date there is no evidence of any study conducted in Namibia that explored the challenges experienced by nursing students during the integration of theory with practice. Therefore, this study sought to explore and describe the challenges experienced by students when applying theory into practice.

\section{Research Design and Methods}

The researchers chose to use exploratory phenomenology. This design was appropriate for this study because it allows a researcher to explore and describe the challenges experienced from the participant's point of view.

\subsection{Context of the Study}

The study was conducted at a satellite campus of a public university located in southern Namibia. The campus started offering nursing programme in 2015.

\subsection{Participants and Sampling}

The total nursing student population in academic year 2017 was 86 . The sample consisted of ten nursing students, five from level one and five from level two. There were no third level students at the satellite campus during the period of data collection as they had relocated to another region for clinical placement during academic year 2017. The researchers employed a non-probability sampling coupled with the use of the purposive sampling method to produce a sample that can be considered to have the characteristics of the population (Burns and Groove, 2013). In addition, all students with prior experience of nursing before joining the four years degree programme were excluded from participation in the study. 


\subsection{Data Collection Procedures}

Data was collected from the participants using two focus group interviews. Both focus group interviews were conducted in the library discussion room at the satellite campus. The duration of the interviews was 50-65 minutes. The researchers use open ended questions and probing techniques to get in-depth information on the integration of theory into practice in clinical settings. The open-ended questions were pre-tested in a pilot study carried out with four participants, who were not part of the main study. Nonetheless, the earlier research procedures involved approaching students in the classroom and explaining the purpose of the study and data collection procedures to them. Five students from each group who expressed their interest to participate in the study were each given consent forms and confidentiality abiding forms to sign prior to the study. All interviews were audio recorded with the participants' permissions. Field notes were also used by the researchers to record non-verbal cues. At the end of the discussion, member checking was conducted to confirm with the participants whether what was recorded was a true reflection of their challenges. Data saturation was also reached at the end of the second focus group discussion.

\subsection{Data Analysis}

Content analysis was used to analyse the data attained from the participants (Burns \& Grooves, 2013). In addition to field notes, data obtained from the focus group interviews were transcribed in verbatim and coded by the researchers. A list of all similar codes were grouped together to form categories and then themes.

\subsection{Quality Measures}

Strategies for ensuring trustworthiness of data in this study were ensued through the use of the Lincoln \& Guba's (1985) criteria: credibility, transferability, dependability and confirmability. Credibility was ensured by prolonged exposure with participants and member debriefing made soon after data collection, which ensured that the participants could view transcripts of the interviews to verify whether they were a true reflection of what they had given during the interview. Transferability was ensured by collecting data up to saturation point. In addition, the researchers provided detailed descriptions of the results. Dependability in this study was enhanced by providing a dense description of the research methods used and its implementation, as well as by describing the steps that were taken to collect data and how the data was analysed. Confirmability was ensured by discussing the research process and findings with peers, with the researchers maintaining reflexivity by writing down their perceptions and beliefs so they would not influence findings and decisions made in the study.

\subsection{Ethical Considerations}

The researchers obtained ethical clearance from the Research and Publication Committee at University of Namibia and the Ministry of Health and Social Services prior to the commencement of the study. Written consent forms and focus group confidentiality abiding forms was completed by the participants prior to their involvement in the study to verify consent and confidentiality (Burns \& Grove, 2013). Data attained from the focus group interviews were kept safe in the researcher's computer with special password. To maintain anonymity, the participants' real names were not used and instead they were identified by codes.

\section{Findings}

\subsection{Description of Participants}

Ten nursing students of the Bachelor of Nursing Science degree programme participated in the study. The participants consisted of five students in their second year level of study and five in their first year level of study. None of the participants had failed a study module since beginning their training. Finally, there were $8(80 \%)$ female participants and $2(20 \%)$ males, a gender distribution that is common as females in Namibia dominate the nursing profession.

\subsection{Presentation of Findings}

Four themes emerged from the challenges experienced by nursing students when integrating theory with practice. The themes are outlined below.

Theory versus practice: This involves the disparities between the teaching that occurs in the nursing school and the clinical experience and experiential practice that the nursing students experience within the clinical settings.

Limited resources in clinical settings: Another critical feature refereeing to the way limited human resources and constrained physical space impacted on the participants' ability to carry out their tasks in the clinical setting. Furthermore, scarce medical supplies to demonstrate procedures, adversely affected the participants' ability to conduct their work at clinical settings.

Discriminatory attitudes: This entails negative attitudes of health care providers. 
Communication: This entails communication barriers that hinder the integration of integrate theory into practice.

\subsection{Theme One: Theory Versus Practice}

\subsubsection{Category one: Theory-practice gap}

The inconsistency between theory and practice in the clinical setting compel the nursing students to feel discouraged and confused. This arises from the recognition that the learned knowledge taught in the classroom is ideological, and is not in harmony with the real clinical settings. The following comments were made on the issue:

"“........First of all" based on theory things, we supposed to apply what we are taught in classroom into clinical practice, but when it comes to clinical practice you find that nurses are doing different things and we do not really apply what we are taught in class. I do not know whether those nurses are used to their system of doing things and then it will be difficult for us to apply what we were taught in class, thus make it difficult to us integrating theory into practice." (P) (Note1)

"Like for me personally, the challenge is that sometimes when the things that you are taught in class are contradicting to those you find at the hospital and you ask sister at the hospital or you want to tell her/ him that what you are doing is contradicting what we learned at school. That leads us into confusion, "basically that is it." (P5).

This denotes a view that students identified the inconsistency between theory and practice in the clinical settings compel the nursing students to feel discouraged and confused.

\subsubsection{Category two: Comprehensive care versus task-orientated care}

The current study participants noticed that the care provided by clinical staff was more task-orientated. The care did not resemble the comprehensively taught skills and embedded knowledge obtained prior to entering the clinical setting. The participants even started questioning the quality of care rendered to patients and described it as putting the patients' life at risk. The examples below outline some of the procedures that nurses performed wrongly in clinical setting as remarked by participants:

"Partograph" is not opened during labour but after the woman has delivered" " nurses will just write the information" all the participant's started" (laughing) ' and they do not want us to open a partograph during latent phase." (P2)

"Another thing I saw that I do not know whether is correct or I am the one who is wrong is that during cord traction some nurses put forceps like that (demonstrating) and yet they are supposed to put it like that (demonstrating the right way) is correct nee? Some nurses when doing cord traction, are just pulling up and down which is contraindicated." (P4)

Thus, means that students noticed that the care rendered to patients in clinical area is more of task- oriented and differ to what they learned before entering clinical settings.

\subsubsection{Category three: Limited cases or exposure to clinical practice}

The main challenge noted in this study as preventing students from integrating theory into practice was lack of exposure to clinical cases. The students' remarks below are instructive:

"I do not think it was a good idea to bring a school of nursing here, no! I do not support it " (frown on the face), because most of the cases that we are doing here are so limited. It has almost become a daily thing to be doing what people are doing here but nothing of what is in your book is there so, you do not learn anything! One day you will become a registered nurse in charge of a ward and you do not know what to do." (P1)

"We cannot really fulfil our learning objectives at that hospital (point on the side where the hospital is located), because, there are no cases at all, you only find maybe one, two or three cases and we need a lot of cases for our practical books and for our experience. Most of time they send us to do minor work or I can say something that is not in our scope. That's what we are always asked to do, so we miss all the procedures that we are supposed to do." (P2)

Thus, the above participant's responses confirm that nursing students lacked exposure during clinical practice and also indicate that the students appeared dissatisfied and distressed about the issue.

3.3.4 Category four: Limited time for clinical practice

The participants felt that the time allocated for clinical practice is too limited. Some of them struggled to complete the required procedures during that time. This forced some students to work during the recess or holiday in order to complete their practical books. The quotations below reflect some of the challenges faced by students regarding limited time for clinical practice:

"I sometimes think that the time that we are given for clinical practice is too limited for us. This is because you find that 
the cases that we are supposed to know happen at that time when we are not at clinical practice. That could be the best time for us to learn those cases and so we are really limited with cases." (P2)

"No"' because of limited time and exposure at the end of the day you end up working during the time you are supposed to rest. For example, you work during the recess or holiday and then when you come to resume your school work you will be exhausted and you end with nothing" (P5).

Thus, the above participants' responses confirm that nursing students are not happy with clinical time allocation.

\subsection{Theme Two: Limited Resources in the Clinical Settings}

\subsubsection{Category one: Lack of equipment}

In the current study participants reported that there was a lack of resources in clinical setting. These shortages, such as that of equipment used to provide nursing care, have a negative influence on the integration of theory into practice. Participants clarify below:

"'Mhu' " the shortage of like materials or equipment is a challenge. It makes us not to apply theory very well into practice because sometimes you learn in theory that you have to use certain equipment but then when you get to a facility you find out that the thing is not there. So it is a big challenge!" (P5)

\subsubsection{Category two: Lack infrastructures}

The study's participants study raised a concern about lack of rooms for screening at public health facilities as the main factor why they found it difficult to integrate theory into practice. The participant emphasised that:

"Some facilities do not have supportive structures for cases when dealing with a client or patient. As a result you must first create privacy every time. It is also like there is too much rush in practice; we do not get time to actually practice those things. Some clinics, for example the clinic in town, at Ante Natal Care there, privacy is compromised!" (P7).

"We are so many in a room. And people are just coming in and going out as students are so many and the coming and going out compromises patients' privacy!" (P6)

Above statements indicate that lack of equipment's and infrastructures as the main factors that prevented students to integrate theory into practice.

\subsection{Theme Three: Discriminatory Attitudes in Clinical Settings}

\subsubsection{Category one: Negative attitudes of health care provider-s toward students}

The study participants recounted the negativity they face owing to the adverse attitudes and discriminatory tendencies of health care providers. The participants pointed out, in their elaboration of the negative attitudes that:

"There is a problem of having lot of people, like students, we end up having competition so I can say that too many people and nurse's attitudes eee' do not help us in fulfilling our learning objectives." (P1)

"And they like comparing us with students from the training centre. Every time you hear them saying you students don't know anything, you are just shadows here! But seriously these students have different practical books and requirements." (P8)

According to the nursing students, health care providers should be reminded that teaching students is one of their core responsibilities.

\subsection{Theme Four: Communication Barrier}

\subsubsection{Category 1: Language barrier}

Participants reported that there is a language barrier especially with elders. The participant made the following similar comment:

"And also our biggest challenge is the language, sometimes we wish to offer our help to the elderly until they are satisfied, but language is a barrier". (P10).

\section{Discussion of Findings}

The available literature shows that the theory-practice gap is a common problem in nursing education (Carson \& Carnwell, 2007). This study's participants raised a concern about the discrepancy between theory and practice in the clinical settings. The participants emphasised that there is a difference between what is taught in the class room and that which happens in clinical settings. Theory - practice gaps make the nursing students feel confused, owing to the realisation that the learned knowledge taught in the classroom is ideological, and frequently does not connect with the real clinical settings. This explains why nursing students are unable to apply theory into practice. The finding 
above correlated with observations from the studies, such as Tiwaken, Lawrence, Curanto and David (2015) and Chan (2013), which state that nursing students are able to identify the discrepancies between the theory taught in the classroom and what they encounter in practice. Therefore, what is taught in the classroom is not always applicable within the clinical setting or in the hospitals.

Moreover, the study participants reported that the time allocated for the clinical setting was not adequate enough for them to achieve the learning objectives or even to build a rapport with clinical staff. Participants reported that they are expected to be in the hospital for two weeks and still be prepared for theory classes and tests. In addition, the lack of cases sometimes compels the students to work during weekends or school recess in order to complete their practical books. These experiences left them feeling pressured, exhausted and overwhelmed by high performance expectations in a short period. The possible interpretation of this is that the school at the satellite campus adapted two weeks block system that is used by all campuses offering nursing degree programme, whereby students receive theory for two weeks and go for a clinical replacement for two weeks. This, therefore, hinders the students' learning as confirmed in a study conducted by Nolan (1998) that identified that short clinical rotation placements impede learning because students are left with less time to reflect on what they would have learned and discovery new practice skills.

The findings of current study also found the existence of a shortage of resources and its negative impact on the training and attitude of students. The participants pointed out lack of equipment as one of the factors that prevent them from integrating theory into practice. This means that sometimes students are taught in classroom to use certain equipment when conducting a certain procedure but to their surprise when they go to clinical setting such equipment is not available. Instead, the availability of resources, such as infrastructure and medical equipment necessary for practice, is paramount in nursing education (Nxumalo, 2011). The gap between theory and practice is accelerated by various factors including lack of equipment in clinical practice, which makes it difficult for clinical mentors and registered nurses to teach student nurses (Van Dyk, Alberts., Iita \& Small,2002). In addition, literature confirms that financial constraints on healthcare exacerbate the situation, as staff become discouraged and depressed by the lack of resources, leaving them with little energy and time to competently attend to the needs of student nurses (Berg \& Danielson 2007). Hence, the findings of current study revealed that there was a lack of resources and infrastructure, which, as highlighted by the shortage of enough rooms for proper screening at the clinics, was frustrating and forced the students to violate ethical principles such as that of privacy.

The currents study's participants also reported negative attitudes or discriminatory attitudes from the health care providers amongst their challenges to integrating theory with practice in the clinical setting. Participants reported that there was preferential treatment amongst clinical staff towards nursing students from health centre who were training diplomas and certificates. This indicated that the clinical staff preferred to teach or work with students from the training centre and consider them more intelligent than university nursing students. Nxumalo, (2011) points out that positive interpersonal relationships between staff and students play a significant role in influencing the student's ability to integrate theory into practice, while negative interpersonal relationships undermine the students' attempt to integrate theory into practice and puts them at risk of dropping out of the programme. Thus, the study, in concurrence with Nxumalo's (2011) observation, noted the existence of negative clinical staff relations with the students. Reporting that the ill treatment left students feeling marginalised and not motivated to adjust and practice their skills within the units.

The researchers are of the view that the above statement about intelligent is just assumption. A literature search showed that no study has been conducted to ascertain whether the diploma or certificate nursing students are more intelligent than degree nursing students. In addition, the current study results on discriminatory issue are not surprising, as the latest study by Nuuyoma, Louw and Van der Merwe (2017) focusing on feedback in clinical settings notes that students raised a concern about a lack of cooperation between both training institutions and clinical settings.

The current study participants stated that there is a language barrier in clinical settings. The majority of people residing in the district speak Damara/ Nama and Afrikaans. These languages dominate clinical settings, and most non- Damara / Nama and Afrikaans speaking students feel left out and not totally involved in the care of patients. Instead, effective communication in a clinical setting is of paramount importance. It plays a significant role in patient care, just as of language proficiency that has been noted to have a positive influence on learning experiences among nursing students (Odessa, Waelli \& Ricketts, 2014). Communication plays a crucial role in the nursing profession, it strengthens quality health care provided to patients and precludes medico-legal risks, be it written or spoken communication. Thus, as noted in the study, there were cases of communication barriers and these created conflicts in students and they ended up unable to sufficiently integrate theory into practice. 
Furthermore, the participants emphasised that they needed knowledgeable clinical supervisors or mentors who could stay with them during clinical placements for the whole day. However, the satellite campus recently recruited preceptors who will accompany and guide students during clinical placements. The current study findings correlate with findings of recent study conducted by Nuuyoma, Louw and Van der Merwe (2017) in the same setting, where the students identified a need for clinical mentors and proposed time allocation for clinical mentors in their timetable for provision of feedback. The above finding also concur with those from studies conducted by Cassimjee and Bhengu (2006), Waterson et al., (2006) and Maselele, Tjallinks and Norval (2001) who identified that nursing students were receiving inadequate clinical supervision, teaching and accompaniments, as clinical facilitators would stay for three months without doing clinical visits. Therefore, it was not surprising that the student respondents presented with high levels of stress due to limited teaching and supervision and the registered nurse's rejection of their teaching role in the wards.

\section{Conclusions}

It was evident from this study that nursing students have challenges in integrating theory and practice, owing to various factors as pointed out. The study identified four themes, theory versus practice, limited resources in clinical settings, discriminatory attitudes and communication barrier. Furthermore, nursing students appreciated accompaniment and supervision by nurse's educators as an indispensable component of effective clinical teaching and learning. However, the supervision may have no influence on learning when students have limited exposure to clinical cases and face a lack of equipment. Therefore, long-term strategies are recommended for effective integration of theory with practice. In addition, there is a need to continue encouraging nursing clinical instructors and registered nurses from clinical settings to support and guide the students during clinical placement.

\section{Recommendations}

The study recommends that clinical mentors and instructors should provide more guidance, supervision and caring attitudes to nursing students in clinical settings. This will provide a conducive learning environment to the students. In addition, nursing students should be re-located for clinical practice to settings that offer adequate exposure to clinical cases that enable the development of future confident and competent practitioners. Lastly, this study recommends lecturers to properly introduce nursing students to the practical components through appropriate simulation techniques that are applicable in clinical settings.

\section{References}

Bendall, E. (1976). Learning for Reality. Journal of Advanced Nursing, 1, 3-9. https://doi.org/10.1111/j.1365-2648.1976.tb00423.x

Benner, P. (2010). Educating Nurses: A call for radical transformation. San Francisco: Jossey-Bass.

Berg, L. \& Danielson, E. (2007). Patients' and nurses' experiences of the caring relationship in hospital: an aware striving for trust. Scandinavian Journal of Caring Sciences, 21(4), 500- 506. https://doi.org/10.1111/j.1471-6712.2007.00497.x

Greenstock, L., Brooks, P., Malloy, E., Fiddes, P. \& Fraser, C. (2015). Medical students' perceptions of role models in clinical placement. Plos One, 11(3). https://doi.org/10.1111/tct.12063

Chan, Z. (2013). A systematic review of creative thinking/creativity in nursing education. Nurse Education Today, 33(11), 1382-1387. http://dx.doi.org/10.1016/j.nedt.2015.07.15

Carson, A. \& Carnwell, R. (2007). Working in theory practice gap: The lecture practitioner's story. Learning in Health and Social Care, 6(4), 220-230. https://doi.org/10.1111/j.1473-6861.2007.00163.x

Cassimjee, R. \& Bhengu, M. P. (2006). Student nurses' perceptions of their contact time with stakeholders in their clinical instruction. Curationis, 29(4), 47-53. https://www.ncbi.nlm.nih.gov/pubmed/17310744

Corlett, J., Palfreyman, J. W., Staines, H. J. \& Marr, H. (2003). Factors influencing theoretical knowledge and practical skills acquisition in student nurses: An empirical experiment. Nurse Education Today, 23(3), 183-190. https://doi.org/10.1016/S0260-6917(02)00232-0

Davhana-Maselesele, M., Tjallinks, J. E. \& Norval, M. S. (2001). Theory-practice integration in selected clinical situations. Curationis, 24 (4), 4-9. https://doi.org/10.4102/curationis.v24i4.867

Henderson, A., Cooke, M., Creedy, D. K. \& Walker R. (2012). Nursing students' perceptions of learning in practice environments. A review. Nurse Education Today, 32, 299-302. https://doi.org/10.1016/j.nedt.2011.03.010

Mabuda., B., Potgieter, E. \& Alberts U. (2008). Student nurses experience during clinical practice in the Limpopo 
practice. Available from: http://www.scielo.org.za https://doi.org/10.4102/curationis.v31i1.901

Maginnis, C., Croxon, L. \& Croxon, C. (2010). Transfer of learning to the nursing clinical practice setting. Rural and Remote Health, 10(2), 1313-1320. Available from: www.rrh.org.au/journal/article/1313.

Maselele, M., Tjallinks, J. E. \& Norval, M. S. (2001). Theory-practice integration in selected clinical situations. Curationis, 24(4), 4-9. https://doi.org/10.4102/curationis.v24i4.867.

Moeti, M. R., Niekerk, S. E. \& Velden C. E. (2004). Perception of the clinical competence of newly registered nurses in the North West Province. Curationis, 27(3), 72-84. https://doi.org/10.4102/curationis.v27i3.1003

Nabolsi, M., Zumot, A., Wardam, L. \& Abu-Moghli, F. (2012). The Experience of Jordanian Nursing Students in their Clinical Practice. Procedia - Social and Behavioural Sciences, 46(0), 5849-5857. https://doi.org/10.1016/j.sbspro.2012.06.527

Nolan, C. A. (1998). Learning on clinical placement: The experiences of six Australian student nurses. Nurse Education Today, 8(8), 622-629. Available from: https://www.ncbi.nlm.nih.gov/pubmed/10188466

Nuuyoma , V., Louw, A. J. \& Van der Merwe, C. (2017). Feedback in clinical settings: perceptions of nursing students at a small rural district hospital in the southern part of Namibia. Unpublished thesis. Available from: https://scholar.sun.ac.za/bitstream/handle/10019.../nuuyoma_feedback_2017.pdf

Nxumalo, S. J. (2011). Factors affecting theory practice gap integration of student nurses in a selected campus of a nursing college in the Limpopo Province. Unpublished thesis. Available from: uir.unisa.ac.za/bitstream/10500/5133/1/dissertation_nxumalo_sj.pdf

Landers, M. G. (2000). The theory-practice gap in nursing: The role of the nurse teacher. Journal of Advanced Nursing, 32(6), 1550-1556. https://doi.org/10.1046/j.1365-2648.2000.01605.x

Odessa, P. D., Waelli, M. \& Ricketts, T. C. (2014). France's transition to academic nursing: The theory-practice gap. Journal of Nursing Education and Practice, 4(10), 88. https://doi.org/10.5430/jnep.v4n10p88

Papp, L., Markkanem, M. \& Von Bonsdorff, M. (2003). Clinical environment as learning environment: Student nurses perceptions concerning clinical learning experiences. Nurse Education Today, 23, 262-268. https://doi.org/10.1016/S0260-6917(02)00185-5

Rikhotso, S. R., Williams, M. J. S. \& De Wet, G. (2014). Student nurses perceptions of guidance and support in rural hospitals. Curationis, 37(1), 1164. https://doi.org/10.4102/curationis.v37i1.1164

Saifan, A., Safieh, H. A., Milbes, R. \& Shibly, R. (2015). Suggestions to close the gap in nursing education. International Journal of Advanced Nursing Studies, 4(2), 62-68. http://doi.org/10.14419/ijans.v4i2.4318

Siganga, T. \& Jeggels, J. (2014). The experiences of trained nurse preceptors regarding their clinical teaching practice in the Western Cape. Magister Curationis Thesis. Available from: http://etd.uwc.ac.za/xmlui/handle/11394/3880

Smith, K., Clegg, S., Lawrence, E. \& Todd, M. J. (2007). The challenges of reflection: Students learning from work placements. Innovations in Education and Teaching International, 44(2), 131-141. https://doi.org/10.1080/14703290701241042

Tiwaken, S. U., Lawrence C., Curanto, T. \& David, T. (2015). The Real World: Lived Experiences of Student Nurses during Clinical Practice, International Journal of Nursing Science, 5(2), 66-75.

Thwala, F. N. (1999) Midwives' Experience of their Clinical Education at a Nursing College in Swaziland, Rand Afrikaans University, Johannesburg. Available from: https://ujcontent.uj.ac.za/vital/access/services/Download/uj:10119/CONTENT1

Van Dyk, A., Alberts, U., Iita, H. \& Small, L. F. (2002). Factors that influence the selection of learning opportunities for student nurses in Primary Health Care. Health SA Gesondheid, 7(2), 25-35. Available at: https://hsag.co.za/index.php/HSAG/article/viewFile/641 https://doi.org/10.4102/hsag.v7i2.641

Waterson, E., Harms, E., Qupe, L., Maritz, J., Manning, M. \& Makobe, K. (2006). Strategies to improve the performance of learners in a nursing college-Part 1: Issues pertaining to nursing education. Curationis, 29(2), 56-65. https://doi.org/10.4102/curationis.v29i2.1077

\section{Note}

Note 1. P1 refers to participant and number allocated 